\title{
Cultura, open source y nuevos modos de educarlsel
}

por Ricardo Vega

Palabras clave:

Open Source, Educación, Internel. Cultura Digital

\begin{abstract}
Este rexto busca introducir, abusando del breve espacio comprometido, algunas ideas y proyectos que ejemplifican el valor de la cooperación y el open source en los cambios de las pracricas creativas y educacionales. Vivimos en una sociedad basada en la idea de comperencia, donde se dan incentivos a las personas para seguir sus intereses individuales. Pensar y actuar de manera individual y aislada sería ideal si viviéramos solos en una isla desierta, pero vivimos en sociedades complejas, en constante interacción entre nosorros, de uno a uno, de uno a muchos, o de muchos a muchos. Esta noción tiene diversos origenes, pero es principalmente el economista escocés Adam Smich quien planteó la idea sobre la maximización del beneficio individual, lo que da pie a la manera en que vemos y conformamos una sociedad. Smith plantea que apelando al egoísmo de los individuos para perseguir sus propios intereses se lograria el bienestar general de la sociedad. Asś, la idea de individuos compitiendo constantemente se instala en los hábitos sociales de producción como algo absolutamente natural.
\end{abstract}

\section{Competencia, colaboración, educación}

Sin embargo, basarse en la idea de competencia como un absoluto que rige la sociedad suena incluso artificial al compararla con la vida diaria. Una familia es un núcleo donde se dan prácticas de colaboración, porque importa el nivel mayor que es la familia. Esta idea se puede extender a una fábrica, oficina, etc., donde las personas colaboran para el desarrollo del trabajo común. Con internet y la cultura digital emergen prácticas de trabajo y producción orientadas 
a la colaboración y el open source, las que impactan de manera muy positiva en el terreno de la cducación.

Los sistemas educacionales institucionalizados (privados o públicos) se han orientado a la formación lineal y masiva de individuos, capacitándolos para el trabajo y la eficiencia productiva. Esto es herencia directa de los sistemas de producción taylorista y fordista surgidos de la Revolución Industrial en la Inglaterra de hace ya más de dos siglos. Se basan además estos sistemas en la exclusividad, la formación para la competencia, compitiendo ellos mismos con otras instituciones, lo que los lleva a trabajar con sistemas principalmente cerrados, buscando maximizar sus recursos y beneficios en una lógica mercantilista de la educación, descentrando muchas veces sus prácticas del objetivo educacional principal.

Pero los escenarios están cambiando. El avance en las tecnologías de la comunicación y el procesamiento de información posibilitan la exploración de nuevos usos y prácticas. Existen ya condiciones y mecanismos tecnológicos para la colaboración directa a bajo costo, en gran escala y en nichos muy específicos antes no explorados por el bajo retorno económico de las inversiones. Por ejemplo, ya no se requiere estar en el mismo lugar y al mismo tiempo para participar de la experiencia educativa (cducación on-line), y donde es posible que participen todos los sentidos (multimedia).

\section{Expandiendo la educación}

Educación expandida se refiere tanto al rompimiento de muchos moldes como al impacto de lo tecnológico en la formación. La educación hoy ya es una experiencia posible de tener en cualquier lugar y momento, gracias a los dispositivos conectados a la red. Se pasa de un sistema de formación centralizado orientado a la producción y a la eficiencia, a otro donde prima la interacción, la no-linealidad, la creación y participación.

Así, el individuo hoy como nunca antes tiene acceso a material y mecanismos para su auto-formación gracias a los excedentes de material educativo y creativo existentes hoy en internet. Se vuclve relevante el cómo creamos el trazado de las cosas que queremos aprender, su secuencia y fuentes. Tomándola en nuestras manos, la educación ya no es en masa, se vuelve por fin personalizada, adaptada a nuestros requerimientos. 
La culcura hacker es un buen ejemplo de esto. Basa sus prácticas en el deseo de conocer cómo funcionan las cosas, desarmando los objetos, explorándolos, viendo cómo son por dentro y ojalá transformándolos en otra cosa, dándoles un nuevo uso. Los hackers (con una mala fama inmerecida debido a los crakers y lamers) se nutren de la sorpresa, la alegría del juego, impulsados por la curiosidad, ingredientes principales de la experiencia educativa.

Denominaciones como el DrY (Do It Yourself, hazlo cú mismo), Dwo (Do It With Others, hazlo con otros), EduPunk, ingenieria inversa, Open Science, etc., dan cuenca de la emergencia de prácticas de educación no formal que no esperan a las organizaciones o el Estado para generar experiencia educacional, creando plataformas donde la independencia individual se suma a la voluntad cooperativa de los colectivos. Se centran principalmente en la capacidad que todos tenemos de hacer, modificar y crear cosas sin la ayuda de profesionales o expertos.

La idea del autodidactismo podría verse enfrentada a las críticas sobre la necesidad de una educación formal, pero existen miles de casos de grandes personajes que se formaron sin esa educación formal en los campos donde destacaron, como el inglés Charles Darwin, o el maremático hindú Srinivasa Ramanujan, o Michael Faraday, uno de los grandes científicos del siglo xix.

\section{La cooperación y la educación}

Recurrir a Internet para buscar información es una práctica muy habitual. Muchas personas de todo el mundo publican material educativo autoproducido, con el objeto de compartirlo, sin esperar recompensa económica. Este es un ejemplo de la voluntad de numerosos individuos dispuestos a colaborar y compatir su información. Claro ejemplo de esto es la Wikipedia, de acceso libre y gratuito, alimentada por la voluntad cooperativa de millones de personas en todo el mundo.

La aparición del concepto de open source (fuentes abiertas) ha permitido conocer aspectos técnicos de los diversos aparatos o procedimientos. Sus creadores han optado por hacer públicas elas recertas? sobre el cómo son las cosas por dentro, permitiendo muchas veces la modificación y mejoramiento de sus características iniciales, confiando en la comunidad para aquello. Surgen así prácticas cooperarivas, donde el objetivo es la mejora constante de las ideas y productos en beneficio ya no sólo de pocos individuos, sino que del colectivo. Qué mejor ejemplo que el sistema operativo Linux. Otros casos que se pueden mencionar, especialmente en el área 
creativa, son los proyectos Arduino (hardware open source) y Processing (software open source), creados por artistas y diseñadores para otros artiscas y diseñadores.

\section{Construcción Colectiva del Conocimiento}

El conocimiento es un proceso común, algo creado por todos los seres humanos a lo largo de la historia, algo que no es de nadie y es de todos al mismo tiempo. La programación y uso de licencias libres y open (Creative Commons o GPL) permite que muchas personas que a veces no cuentan con recursos (dinero, tiempo, lejanía, etc.) para una educación formal tengan acceso a material para su propia formación.

Los avances tecnológicos han posibilitado este escenario, donde el conocimiento ya no se genera solamente en los grandes centros de formación o investigación, sino que se convierte en un flujo que sobrepasa las fronteras de las instituciones. Es necesario ampliar la perspectiva para comprender los alcances y cambios que esta infraestructura tecnológica genera en nuestra superestructura de relaciones sociales y simbólicas. La velocidad de cambios aumenta constantemente y se requiere flexibilidad para adaptarse e incorporar las novedades emergentes, y son los individuos los más flexibles para adaptarse, que las pesadas y burocráticas instituciones.

Una sociedad se conforma por un conjunto de personas que pasan de estados individuales a otros colectivos, en constante interacción colaborativa con su medio, generando diversos niveles donde lo individual se mezcla con lo colectivo, y la colaboración complementa a la competencia como dos caras de una moneda. Para entenderlo se zequieren puntos de vista más complejos que no se remitan a la mera reducción del hombre a una máquina individual y egoísta en constante lucha por lograr sus intereses individuales. Es más que eso, es un ser en constante interacción y colaboración con otros, proceso del cual emergen diversos subconjuntos relacionales que dan forma a nuestras sociedades.

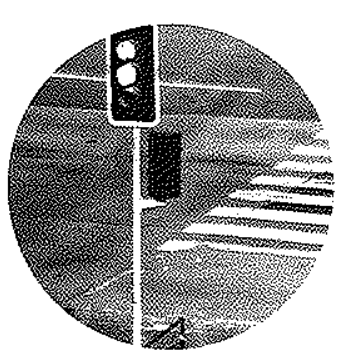

\section{Referencias}

www.ocwconsortium.org

http://www.zemosg8.org/simposio/spip.php?rubriquer

http://es.wikipedia.org/wiki/?tica_hacker

http://www.invisiblelearning.com/

http://www.derechosdigitales.org/azk/

hutp://educalibrc.cl/ 